\title{
miscellany
}

\section{The British Pakistani Psychiatrists Association (BPPA) Awards}

Young Researcher of the YearAward The aim of this award is to promote an interest in psychiatric research among young Pakistani health professionals and students, and to honour and recognise research work that has been published in any peer-reviewed scientific journal. The award is not restricted to any sub-speciality and work carried out in any psychiatric field will be considered. There will be two categories of the award: one for research carried out in Pakistan and the other for research carried out in UK and Ireland.

The BPPA Clinical Audit Award

The aim of this award is to promote an interest in clinical audit among young Pakistani health professionals and students, and to honour and recognise their work. The competition is open to all clinical audit work carried out in any psychiatric field.

\section{New - The BPPA Public Education} Award

The aim of this award is to promote an interest in public education in mental health issues among Pakistani media professionals, artists, health professionals and students, and to honour and recognise their public education work.

All winners and runner-ups will be entitled to memorial shields and cash rewards. For further information and nomination forms for any of the above awards please email secretary@bppauk.org or visit the BPPA website: www.bppauk.org. All nominations must reach Dr Sohail Qureshi, Secretary BPPA by 31 August 2008 by post. The results will be announced by 30 September 2008.

doi: $10.1192 / p b . b p .108 .021121$

\section{forthcoming events}

\section{International Conference}

on Schizophrenia: IConS III

This conference will take place in Chennai, India, on 17-19 October 2008. The event is organised by the Schizophrenia Research Foundation (SCARF), Chennai, India (WHO Collaborating Centre for Mental Health Research) and cosponsored by the World Psychiatric Association, the World Health Organisation and The Indian Psychiatric Society. A galaxy of international schizophrenia researchers will showcase the best of schizophrenia research in the world. Award for young researchers. For further information please visit www.icons-scarf.org or contact Dr R. Thara, Director, SCARF, India, by email: scarf@vsnl.com or info@icons-scarf.org.

\section{Summer Institute}

\section{on Global Mental Health}

The International Mental Health Centre in partnership with the Institute of Psychiatry (IOP), the London School of Hygiene and Tropical Medicine, and the World Federation for Mental Health is inviting applicants to attend a series of events to be held this summer in London. The International Mental Health Short Course on Methods \& Applications will be held on 18-23 August 2008. This will be followed by The 4th International Mental Health Conference at the IOP on 26-28 August 2008. The World Federation for Mental Health International Provider's Forum: Mental Health and Psychosocial Support in Disasters will run on 28-29 August 2008. Another short course, An Introduction to Qualitative Research Methods, will take place on 3-5 September 2008. For further information about the above and other events visit www.iop.kcl.ac.uk/events/.

doi: $10.1192 / p b . b p .108 .021253$

\section{correction}

However, only $8 \%$ preferred a complete smoking ban which compares with $3.0 \%$ in our study favouring a total ban on hospital premises (Exploration of in-patient attitudes towards smoking within a large mental health trust. Psychiatric Bulletin, 32,

166-169).

doi: 10.1192/pb.32.6.239 